\title{
GESTÃO ORGANIZACIONAL SOB A LÓGICA DA COMPETÊNCIA: APLICAÇÃO NA PEQUENA EMPRESA
}

\author{
ORGANIZATIONAL MANAGEMENT UNDER THE LOGICAL \\ COMPETENCE: AN APPLYING IN THE SMALL BUSINESS
}

\section{LUCIANO MUNCK}

Doutor em Administração pela Faculdade de Economia, Administração e Contabilidade da Universidade de São Paulo (FEA-USP/SP). Coordenador do Programa de Pós-graduação em Administração da Universidade Estadual de Maringá/Universidade Estadual de Londrina (PPGA-UEM/UEL) e Professor da Universidade Estadual de Londrina (UEL) e da Pontifícia Universidade Católica do Paraná (PUC-PR).

Rua Jerusalém, 180, ap. 1.902, Residencial do Lago - Londrina - PR - CEP 86050-510 E-mail: munck@uel.br

\section{MARIANA MUSETTI MUNCK}

Doutoranda em Engenharia de Produção pela Escola Politécnica da Universidade de São Paulo (Poli-USP/SP). Professora da Universidade Estadual de Londrina (UEL). Rua Jerusalém, 180, ap. 1.902, Residencial do Lago - Londrina - PR - CEP 86050-510 E-mail: marianamunk@londrina.net 


\section{RESUMO}

Este estudo, sustentado nas premissas teóricas do modelo de gestão por competências, objetiva explorar, descrever e mudar a sistemática de execução das atividades de uma pequena empresa de consultoria. Orientando-se por autores que propõem a operacionalização do conceito de competências nas organizações, construíram-se quadros de referências para as células da organização de modo que houvesse mais transparência e consistência nas ações de gestão, e isso representa um grave problema das pequenas empresas. Os quadros são compostos de atributos como missão, atribuições, contribuições, indicadores de resultados e competências, todos definidos com base nas estratégias e nos objetivos almejados pela organização. Ante a proposta de não apenas explorar e descrever, mas também de mudar, o estudo utilizou como orientação metodológica a pesquisa-ação. Esse método não se limita apenas a descrever uma situação, mas também pretende desencadear, em certos casos, mudanças no seio da coletividade envolvida. O próprio processo de busca e os resultados alcançados demonstraram, a princípio, que a estruturação de uma empresa por competências gera turbulências iniciais, principalmente pela radicalidade da mudança (neste caso) e pelas particularidades do conceito. A nova estrutura tem provocado mudanças culturais, sobretudo na ação dos gestores que têm agora informações claras sobre as atribuições e exigências cabíveis a cada célula, bem como de seus respectivos indicadores de desempenho.

\section{PALAVRAS-CHAVE}

Estruturação; Competências; Pequena empresa; Mudança; Aprendizagem.

\section{ABSTRACT}

The study being maintained in the model of theory of the competencies management has the objective to explore, describe and change the system of how activities are being developed in a small consulting business. Being oriented by authors who 
have proposed the operation of the concept of competencies in organizations, a frame was built for the reference of the cells of organization in a way that it would be transparent and consistent with management. The frames are composed as the basis of the strategy and objectives desired by the organization. Not only this proposal aims to explore and describe, but also to change, the study used as the basis a action research. The search process and the results have shown, at first, that the structure of a company by its competencies creates some initial conflicts, mainly because the change is so radical and the particularities of the concept. Once the concept is internalized by the components in the organization, the problems decrease and the implementation happens.

\section{KEYWORDS}

Structure; Competencies; Small business; Change; Learning.

\section{INTRODUÇÃO}

Constata-se em publicações hodiernas ligadas à área de gestão organizacional crescente preocupação e discussão sobre novas formas de organizar e gerenciar o trabalho. Entre os temas mais discutidos, encontra-se a "abordagem da competência" que envolve não só aspectos ligados ao gerenciamento de pessoas, mas também da organização como um todo. Ruas et al. (2005) verificaram que de 2000 a 2004 foram publicados 5I artigos sobre o tema em importante congresso e em periódicos da área de administração do Brasil. Outro ponto evidenciado por Ruas et al. é a diversidade de significados dada ao conceito, principalmente quando se trata da competência na perspectiva organizacional. De certa forma, é importante que haja diversidade, pois, dessa forma, conhecem-se aspectos inexplorados ou mal trabalhados por algumas vertentes. A elucidação de pontos de vista difusos e a expansão da base crítica sobre o tema têm contribuído para a revisão de alguns clássicos procedimentos organizacionais. Alguns pontos são comuns entre os principais estudiosos da abordagem da competência: a necessidade de vinculação com a estratégia empresarial, a necessidade de vinculação das competências organizacionais e individuais, a necessidade de conhecer os recursos que constituem as competências, e, finalmente, o fato de que a abordagem está em construção (FLEURY; FLEURY, 200I; DUTRA, 2004; MILLS et al., 2002; BITENCOURT, 200I).

Mesmo diante de lacunas conceituais, o modelo de gestão por competências se apresenta como uma das maiores evoluções em termos de gestão dos últimos 
anos. A possibilidade de nortear e ser norteado pelas ações estratégicas o posiciona, no atual contexto competitivo, como uma das principais ferramentas de diferenciação em termos de gestão. Em estudo realizado por Barbosa e Rodrigues (2005), evidenciou-se que, de irg das maiores empresas do Rio de Janeiro, Minas Gerais, São Paulo e Rio Grande do Sul pesquisadas, 84 tinham um modelo de gestão por competências implantado ou em implantação.

A presença do modelo em grandes empresas é acentuada, contudo não se encontraram estudos que apresentassem a discussão ou a aplicação do modelo em pequenas empresas. Um estudo sobre a proposta de uma metodologia para identificação de competências em uma pequena empresa foi realizado por Valle e Macke (2005), mas limitou-se a descrever a vinculação das competências às fases de desenvolvimento da pequena empresa, de acordo com uma determinada corrente.

Segundo Souza (I995) e Pinheiro (I996), as pequenas empresas apresentam maior flexibilidade e simplicidade para adaptar-se às transformações do mercado, às mudanças tecnológicas e às novas exigências no que se refere à gestão. Todavia, apesar da natural flexibilidade e simplicidade, segundo dados do Sebrae de 2006, aproximadamente 59,9\% das pequenas empresas criadas decretam falência nos primeiros quatro anos de sua existência. De acordo com os empresários, o principal motivo da falência é a situação econômica. No entanto, segundo os consultores do Sebrae, isso ocorre porque essas empresas não têm a estrutura necessária para administrar seus negócios.

Com base nesse contexto, o presente artigo apresenta um estudo que descreve o processo de (re)estruturação organizacional e gerencial de uma pequena empresa de consultoria, de acordo com os preceitos da pesquisa-ação e a lógica da competência. Para tanto, o estudo baseou-se em autores como Fleury e Fleury (200I), Zarifian (2003), Boterf (1995, 2003) e num modelo adaptado de Ruas (200I). Em cada célula, definiram-se a missão, as atribuições, as contribuições, a entrega, os indicadores e as competências exigidos. Espera-se, com este trabalho, contribuir com a ampliação das possibilidades de aplicação de modelos de gestão estruturados em pequenas empresas. Além disso, o estudo explora possibilidades de uso prático da abordagem da competência, ainda em construção.

\section{COMPETÊNCIAS: ORIGENS, CONCEITOS E APLICAÇÕES}

Os registros mais significativos sobre o tema competências remontam à década de I970, com os estudos realizados por David McClelland (I973), em que se procuraram diferenciar competências de temas como aptidões, conhe- 
cimentos e habilidades, com o propósito de conceituar competência como uma característica subjacente a uma pessoa para que esta possa ter um desempenho diferenciado perante uma tarefa ou situação. Em I982, Boyatzis recuperou estudos sobre competências dos gerentes e identificou um conjunto de características e traços que, segundo ele, proporcionam um desempenho superior. Na época mencionada, como ainda hoje, a competência estava muito ligada ao paradigma taylorista-fordista e era uma forma mais moderna de trabalhar a qualificação dos funcionários com o objetivo de obter desempenhos superiores. Definia-se um estoque de conhecimentos, habilidades e atitudes (CHA) que permitiam ao indivíduo, em seu cargo ou função, alcançar resultados diferenciados.

Alguns dos principais conceitos envolvidos na competência individual são:

- “um saber agir responsável e reconhecido, que implica mobilizar, integrar e transferir conhecimentos, recursos e habilidades que agreguem valor econômico à organização e valor social ao indivíduo" (FLEURY; FLEURY, 200I, p. 2I).

- "Competente é aquele que ao examinar uma situação problema pondera, aprecia, avalia, julga e, em seguida, visualizando diferentes ângulos, encontra a solução ou decide" (ANTUNES, 200I, p. I7).

- "Competência é a faculdade de mobilizar diversos recursos cognitivos - que inclui saberes, informações, habilidades operatórias e principalmente as inteligências - para, com eficiência e eficácia, enfrentar uma série de situações ou problemas" (PERRENOUD, I999).

- "Competência gerencial é a capacidade de mobilizar, integrar e colocar em ação conhecimentos, habilidades e formas de atuar, chamados recursos de competência, a fim de atingir/superar desempenhos configurados na missão da empresa e da área” (RUAS, 200I).

Percebe-se que um ponto é comum nas definições sobre competência individual: a capacidade de mobilizar recursos perante uma demanda.

Com o propósito de ampliar o foco das competências nas organizações para além do conceito de qualificação ante um cargo ou função, um grupo de estudiosos franceses, entre os quais Zarifian (2003) e Boterf (2003), relacionou a competência à noção de capacidade de realização ante uma situação que emerge. Não adianta uma pessoa possuir um estoque de conhecimentos e habilidades se estes não forem ativados numa situação emergente. Segundo Boterf (1995), a competência emerge da situação que a precede e se legitima na eficácia alcançada e reconhecida. Essa linha reforça a importância do terceiro componente da competência, "atitude", tendo por base o CHA. Boterf (I995) salienta que a competência do indivíduo não é um estado, ela é resultado do cruzamento de 
três eixos: a formação do indivíduo - sua biografia e socialização -, sua formação educacional e sua experiência profissional. Essa definição joga luz na necessidade de formação e entendimento amplos do indivíduo para se trabalhar o conceito de competência. Com base no princípio de que a competência do indivíduo pode ser limitada por qualquer um dos três eixos propostos por Boterf, conclui-se que o eixo "biografia e socialização", de difícil mudança em um profissional constituído, torna-se uma variável fundamental para definição de critérios de contratação ou desenvolvimento de competências. Uma limitação nesse eixo tende a retardar ou impedir o desenvolvimento de determinadas competências necessárias em dado tempo.

Dutra (2004), ao intercalar a visão norte-americana e a francesa, insere na discussão sobre competência os conceitos de "entrega", "complexidade" e "agregação de valor". Entrega seria o que realmente o indivíduo quer e tem condições de gerar para a empresa em termos perenes; não seria a capacidade de gerar resultados atípicos, seria a capacidade de gerar resultados contínuos num determinado nível de complexidade. Já a complexidade trata da crescente exigência do indivíduo nas diversas ações e funções da empresa. Uma tomada de decisão de um chefe de produção não tem a mesma complexidade da tomada de decisão de um diretor de produção, pois as variáveis envolvidas na decisão são diferentes em relação às exigências requeridas para seu conhecimento e manuseio eficaz.

Além disso, a amplitude dos efeitos da decisão é diferente embora os dois ocupem postos de liderança. Já a agregação de valor está intimamente ligada à complexidade das tarefas. Quanto mais complexas forem as tarefas, mais valor o indivíduo que as executa gerará para a empresa.

Ampliando o zoom do conceito de competências para a esfera organizacional, encontram-se suas origens na corrente que apregoa que as organizações fundamentam-se em um conjunto de recursos (marca, tecnologia, pessoas, modelo de gestão) que, quando identificados e articulados, formam seus limites e possibilidades de diferenciação. Essa discussão nos remete ao debate empreendido por Chandler Junior (I990) em I976, no qual o autor identificou que grandes corporações norte-americanas redefiniram sua estratégia com base nas mudanças no ambiente; essa redefinição implicava mudanças na sua estrutura, na reorganização de seus recursos internos. Para a corrente da empresa baseada em recursos (resource based view of the firm - RBVF), são os recursos que a empresa possui e não o ambiente que devem iniciar o processo de definição de estratégias. Segundo Mills et al. (2002), seguidor da corrente RBVF, a formulação das estratégias deve focar um conjunto específico de recursos que garantam bons resultados no longo prazo. Segundo o autor, é importante que se distingam recursos de competências. As competências seriam a operacionalização sistêmica dos recursos (tecnologia, pessoas, marca, carteira de clientes). As competências dependem, 
portanto, da capacidade da organização de articular seus recursos para fazer frente a uma demanda. Prahalad e Hamel (I990), eminentes representantes dos estudiosos sobre as competências organizacionais, reforçam a importância que a articulação e o conhecimento dos recursos têm no alcance de estratégias e formação das competências essenciais (core competences). Essas competências seriam as que sustentariam os diferenciais da empresa ao longo dos anos.

Competências organizacionais seriam as competências que mantêm o negócio funcionando lucrativamente e, portanto, atuam como diferenciais competitivos. Ou seja, capacidades operacionais/funcionais diferenciadas que proporcionam perenidade à organização. Já o conceito proposto por Prahalad e Hamel (I990), inicialmente chamado de core competences nos Estados Unidos e disseminado no Brasil como competências essenciais, diz respeito à parte estratégica da empresa que, resumidamente, dificilmente pode ser copiada num curto espaço de tempo. A competência essencial, na maioria das vezes, não é natural e se difere de um portfólio de produtos ou serviços e se alinha mais com um portfólio de competências. Goddard (I997) entende que os diferenciais externos que tornam uma empresa bem-sucedida são sustentados por diferenciais internos. Dessa forma, infere-se que as competências essenciais são a operacionalização sistêmica das competências organizacionais. Segundo Goddard (I997), as competências essenciais são a origem das habilidades da empresa para transmitir aos seus clientes um valor agregado excepcional perante os concorrentes, entretanto elas não podem ser confundidas com tecnologias de ponta, processos de classe mundial ou outras definições relacionadas a questões operacionais. Esse autor entende que o grande produto da Sony não foi o "Walkman" ou o "Triniton", mas a competência de criá-los e produzi-los. O grande diferencial da Disney não são seus personagens, mas a capacidade de fazer as pessoas se entreterem. Oliveira Júnior (200I, p. I27) enfatiza que a competição se dá em torno de competências e não de produtos ou serviços. Ao contrário dos recursos físicos, que se deterioram com o tempo, elas desenvolvem-se à medida que são aplicadas e compartilhadas. Elas ligam os negócios existentes e são o "motor" para o desenvolvimento de novos negócios.

Um ponto importante ainda a destacar no assunto é a questão dos recursos de competências. Antes é importante ter algumas informações conceituais sobre isso. Wernerfelt (I994) conceitua recursos como algo que pode ser pensado como um ponto forte ou um ponto fraco da empresa. Alguns exemplos de recursos são: nome da marca, conhecimento tecnológico desenvolvido na empresa, emprego de pessoal qualificado, contrato de negócios, maquinário, procedimentos eficientes, capital etc. Daí a importância da articulação. Marca e tecnologia, por exemplo, isoladas não levam a empresa muito longe. Posicionar-se em relação aos recursos e sobre sua articulação conduz para o alcance de 
consistência e integração nas ações. A capacidade de articulação de recursos é própria da empresa, assim, quanto mais inimitáveis e insubstituíveis forem os recursos, maior será a dificuldade de cópia da estratégia pela concorrência. A visão de empresas baseada em recursos é mais uma tentativa de explicar por que algumas empresas são capazes de estabelecer vantagens competitivas duradouras (MILLS et al., 2002).

Segundo Zarifian (2003), existem cinco competências necessárias a uma organização:

- Competências sobre processos (processo do trabalho);

- Competências técnicas (conhecimento específico sobre o trabalho a ser realizado);

- Competências sobre a organização (saber organizar os fluxos de trabalho);

- Competências de serviço (qual é o impacto do serviço sobre o consumidor final?);

- Competências sociais (incluem atitudes que sustentem os comportamentos das pessoas).

Observa-se que todas as competências propostas por Zarifian são dependentes da existência de recursos diversos que deverão ser articulados.

Fleury e Fleury (200I), com o propósito de operacionalizar conceito, posicionam a competência em um ciclo, que poderia ser comparado a um ciclo de aprendizagem. Esse ciclo, não necessariamente, possui um início ou um fim, pois as estratégias são formuladas com base na operacionalização sistêmica dos recursos (competências organizacionais), que, por conseguinte, são influenciados e modificados pela resposta obtida pela estratégia, o que novamente provoca e até mesmo exige novas configurações dos recursos, que poderão ou não implicar modificações ou a necessidade de uma nova estratégia. Uma proposta de mudança no ciclo apresentada por Fleury e Fleury (200I), demonstrada na Figura 2, posiciona a aprendizagem, embora se entenda que ela ocorra em todas as fases do processo, no final formal deste. Nessa fase, ela tende a ocorrer com maior parâmetro e consistência, para melhor orientar a possível revisão dos recursos e de sua articulação ante as necessidades estratégicas.

O processo proposto na Figura 2, o qual lastreou a elaboração dos quadros de competências para as células da organização pesquisada, fundamenta-se no seguinte raciocínio:

- Inicialmente, a organização identifica seus recursos ou a falta ou o excesso destes. 
- Em seguida, ela trabalha no preenchimento de lacunas, se houver, e depois na articulação, a fim de constituir ou identificar competências.

- Com base nas competências identificadas, estuda-se a melhor estratégia a ser utilizada.

- Na execução da estratégia, a aprendizagem ocorre por meio de erros, acertos, carências e sobras, no que se refere a recursos e competências.

- Conseqüentemente, desencadeia-se um processo de mudança para adquirir, aprimorar ou corrigir os recursos e as competências.

Depreende-se da exposição até aqui realizada que a competência individual tem íntima ligação com as competências organizacionais e conseqüentemente com o sucesso da estratégia, na maior parte dos casos. A articulação de recursos, chave do processo, é totalmente dependente da competência individual em realizá-la. Portanto, a articulação e a rearticulação de recursos perante as demandas, passando por um processo de aprendizado, tendem a conduzir para uma facilitação da aquisição, da legitimação e do reconhecimento da competência.

Nesse sentido, Ruas (200I) evoca a importância da integração da competência com o processo de aprendizagem. Além disso, define alguns outros itens que seriam importantes para lastrear a configuração e a medição da competência na organização, tendo como ator principal o gerente. $\mathrm{O}$ autor propõe a seguinte lógica: considerando uma área gerencial qualquer (neste estudo, optou-se por células), inicia-se o processo pela apropriação da estratégia empresarial pela célula, fazendo-a manifestar-se em sua missão e em seus objetivos. Com base na missão e nos objetivos, definem-se os indicadores de desempenho. A partir das diretrizes da missão da célula, são constituídas as atribuições gerenciais, as quais são orientadas por valores, políticas, normas e procedimentos presentes na cultura, definindo a atuação da gerência. Essa última, realizada em situação específica que envolve condições e restrições próprias à situação de trabalho, delibera a competência. Assim, segundo Ruas (200I), na verdade, a atuação da gerência que mobiliza recursos e capacidades ante uma demanda compõe a competência. A validação e a legitimação da competência, critério final para sua "existência", ocorreriam pela confrontação com os resultados esperados. Somente nesse momento, destaca o autor, é possível apreciar qual é o nível de competência da atuação gerencial ou, expandindo, de qualquer outro profissional.

Em suma, o enunciado das "atribuições" define aquilo que deve ser feito para o cumprimento da missão. A performance permite avaliar, por meio de indicadores predeterminados, em que percentual o objetivo foi atingido. Um gestor ou profissional terá seu nível de competência definido pelo confronto entre o alcançado e o esperado para sua atividade. Fica o desafio de medir a competência em questões qualitativas como "pensar estrategicamente". 
FigURA I

ESTRATÉGIA E COMPETÊNCIAS

ESSENCIAIS
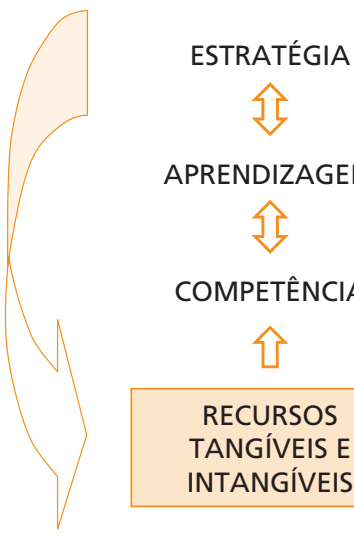

APRENDIZAGEM

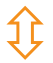

COMPETÊNCIA

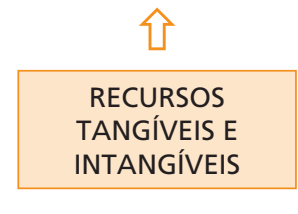

Fonte: Fleury e Fleury (200I).

\section{FIgURA 2}

CICLO DE APRENDIZAGEM

PARA FORMULAÇÃO DE

ESTRATÉGIAS E FORMAÇÃO

DE COMPETÊNCIAS

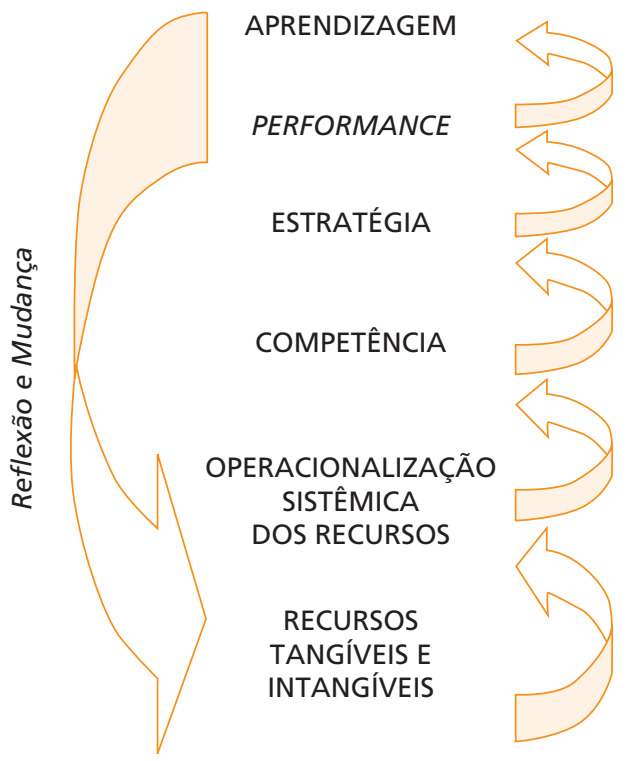

Fonte: Elaborado pelos autores.

\section{POR QUE USAR O MOdELO de GESTÃO POR COMPETÊNCIAS EM UMA PEQUENA EMPRESA?}

Terence (2002) afirma que as características mais citadas na literatura sobre pequena empresa são as especificidades em relação à sua estrutura interna. Escrivão Filho (I995) destaca que as condicionantes organizacionais surgem de variáveis como tecnologia, comportamento, estrutura, decisão e estratégia, as quais apresentam particularidades quando tratadas na pequena empresa. Contudo, Pinheiro (I996) destaca que o nível administrativo de pequenas empresas é bastante rudimentar, o que proporciona inconsistência nas ações e inexistência de nortes que definam claramente os papéis de seus ocupantes e os níveis de responsabilidade correspondentes.

Golde (I996) expõe que o proprietário da pequena empresa, normalmente seu principal gestor, executa quase todas as funções, o que o sobrecarrega e 
não permite que ele dedique adequadamente às questões estratégicas. De acordo com Longnecker et al. (I997), os pequenos empresários são generalistas e não dispõem de apoio profissional nos campos das finanças, dos recursos humanos, da produção e do marketing, o que limita sensivelmente sua capacidade de resolução de problemas de gestão. Nesse contexto, uma estruturação por competências contribui não só para a clarificação da carência no que se refere a elas, mas também para a organização de ações que tenham como objetivo supri-las. Conseqüentemente, a organização tende a melhorar a distribuição do tempo do proprietário/gestor e melhor dividir as responsabilidades.

Assim, pela realidade encontrada na empresa analisada, vislumbraram-se significativas contribuições do modelo de competências para nortear suas atividades e ações. Como já salientado, a maior causa de falência das pequenas empresas é a falta de profissionalismo na gestão. As necessidades e exigências percebidas no que se refere à organização de recursos e as características de flexibilidade, abertura e integração já presentes na empresa facilitaram o processo. Na fase exploratória da pesquisa, verificou-se a existência da informalidade e casualidade nas ações da empresa, o que a estava prejudicando e provocando conflitos na tomada de decisão e, conseqüentemente, no próprio processo de execução das atividades. Contudo, concomitantemente, verificou-se a possibilidade de articulação dos recursos existentes com o objetivo de configurar competências e definir estratégias, de acordo com o fluxo proposto na Figura 2. Enfim, iniciou-se a construção de um modelo de gestão que, a princípio, contribui para a eliminação da principal causa de falência das pequenas empresas: a ineficiência da gestão.

\section{PROCEDIMENTOS METODOLÓGICOS}

Com o objetivo de explorar, descrever e mudar a realidade organizacional de uma pequena empresa de consultoria, de acordo com o prisma conceitual da gestão por competências, o presente estudo utilizou como orientação metodológica a pesquisa-ação. Esse método não se limita a apenas descrever uma situação, ele pretende, sim, em certos casos, desencadear mudanças no seio da coletividade implicada. A organização em análise, embora com uma atuação de oito anos no mercado, não possuía uma estrutura formal de organização de suas atividades. Diante da necessidade de organização e das contribuições oferecidas pelo modelo em estudo, optou-se por construir e formalizar sua estrutura de prestação de serviços com base no conceito de competência. Com foco no aprofundamento da aplicação prática do conceito em uma pequena empresa, identificou-se, descreveu-se e propôs-se um mecanismo para a organização das competências da empresa. Para tanto, serviu-se das quatro etapas sugeridas por Thiollent (I997, p. 58): 
I) Fase exploratória: diagnóstico da atual situação, o qual envolveu levantamento das práticas de gestão atuais, de questões culturais, da formação dos colaboradores, de documentos referentes a projetos desenvolvidos, do processo de comunicação interna e de formas de avaliação de resultados.

2) Fase da pesquisa aprofundada: inicialmente, os membros da organização participaram de dinâmicas envolvendo treinamentos sobre os conceitos e as aplicações do modelo de competências. Em seguida, os membros foram entrevistados de acordo com um roteiro de questões abertas sobre estratégia empresarial, estrutura organizacional, competências necessárias e existentes, atributos necessários para ocupação de funções e atuação na organização, e critérios de avaliação de resultados.

3) Fase da ação: lastreando-se pelos dados da investigação, propôs-se e construiuse a nova estrutura em células. As exigências de cada célula foram definidas conforme adaptação das propostas de Ruas (200I, 2005), essencialmente, e demais autores pesquisados, o que constituiu os denominados quadros de competências. Esses quadros de competências envolvem a descrição da missão, das atribuições, das contribuições, das entregas, dos indicadores de desempenho e, finalizando, das competências. Todos alinhados entre si e envolvidos na estratégia organizacional.

4) Fase da avaliação: nessa fase, por um período de três meses, avaliou-se, com base em indicadores qualitativos como coerência nas ações, aderência às propostas estratégicas, satisfação interna, integração entre os membros e organização do processo de tomada de decisão, o funcionamento da nova estrutura. Chegou-se então à estrutura em seguida descrita.

A análise e interpretação dos dados se deram de forma exclusivamente qualitativa, envolvendo percepções subjetivas e objetivas dos autores e membros da organização sobre os itens exigidos pelos quadros, todavia houve a preocupação de lastrear e revisar as percepções com base nos conceitos e nas definições estudados. Dessa forma, os quadros de competências foram fundamentados na triangulação entre o referencial teórico, dados levantados na empresa e revisão de necessidades e percepções sobre a implantação do conceito.

\section{A EMPRESA}

A $2 \mathrm{M}$ Associados, empresa-objeto do presente estudo, localizada no norte do Paraná, presta serviços na área de gestão e ensino. Iniciou suas atividades em I994 com um único serviço, o treinamento in company. Atualmente, além do treinamento, a empresa trabalha com recrutamento e seleção, outplacement e 
assessoria na área educacional. Em especial, atua na elaboração e comercialização de cursos de pós-graduação em parceria com faculdades privadas. A empresa fatura anualmente cerca de $\mathrm{R} \$ 200.000,00$ e conta com quatro colaboradores efetivos - uma psicóloga, uma educadora, um digitador, um programador/ designer/assistente administrativo - e dois sócios-gestores - o diretor administrativo e a diretora financeira. Além desses, conta com inúmeros parceiros que prestam serviços conforme demanda.

O principal gestor é o diretor administrativo que procura atuar como facilitador/coordenador das atividades. A diretora financeira encarrega-se de controlar e distribuir recursos e negociar os projetos da organização, principalmente no aspecto financeiro. A psicóloga e o programador/designer são responsáveis pelo gerenciamento e pela estruturação dos cursos de pós-graduação. A educadora e o programador/designer atuam na busca por novas oportunidades, planejamento, negociação e acompanhamento de treinamentos empresariais. O programador/ designer que, atualmente, também atua como auxiliar administrativo dá suporte técnico e administrativo aos serviços prestados. Todos, com exceção do digitador, que atua no auxílio gráfico, trabalham com remuneração variável. Ao digitador cabe o suporte no que se refere à digitação dos projetos, tem salário fixo enquanto se encontra em processo de aprendizagem e crescimento.

O trabalho, em sua maior parte, é realizado em equipe, com troca permanente de informações entre as células envolvidas (ver Figura I). Percebeu-se que a estrutura em células já era utilizada informalmente, coube a este trabalho formalizá-la. A mobilização da equipe visa atingir as metas estabelecidas e o contínuo crescimento do grupo como um todo e das pessoas que o compõem. As ações individuais e da equipe são determinadas em reuniões rápidas e permanentes, nas quais se definem as metas de cada célula.

\section{APRESENTAÇÃO E DISCUSSÃO DOS RESULTADOS}

A empresa, tendo por referência os levantamentos e as discussões com os membros, teve sua missão identificada como:

prestar assessoria e serviços na área de gestão e educação gerencial de forma diferenciada e customizada, almejando expandir a aplicação de conhecimentos consistentes e ser agente multiplicador do saber crítico, coerente e inovador. 
Em relação às estratégias vigentes, observaram-se os seguintes aspectos: utilizar a experiência acumulada para manter o apoio e a força de penetração de instituições de Ensino Superior na oferta de cursos de pós-graduação; atender a públicos determinados como hospitais, faculdades e empresas de setores específicos com treinamentos customizados e adequados à sua realidade; e oferecer cursos ministrados por profissionais atuantes tanto no campo acadêmico quanto no prático, de diversos locais do sul e sudeste do País, visando à troca freqüente de experiências e aprendizagens.

Em resumo, a empresa praticava à época da pesquisa a estratégia de evitar retrabalho e desperdícios de recursos por meio da integração e organização de seus serviços, mantendo-se a qualidade conquistada e o preço acessível.

Depois de discussões sobre modelos de gestão com os funcionários, consideraram-se as características necessárias a uma empresa prestadora de serviços de consultoria, tais como: valores e objetivos comuns, informalidade, liderança por competência reconhecida, multifuncionalidade, comunicação lateral e aberta, e autonomia no aproveitamento de oportunidades. Como a empresa já possuía a característica de comunicação informal, flexibilidade e trabalho em equipe, entendeu-se que uma estrutura organizacional que valorizasse essas características e proporcionasse certa formalidade ao modelo de gestão seria a ideal. Assim, a estrutura organizacional proposta para a empresa foi aquela realizada em células. A estrutura proposta está representada na Figura 3, em que as linhas demonstram o contínuo contato e a integração de todas as células.

\section{FIGURA 3}

ESTRUTURA ORGANIZACIONAL DA 2 M ASSOCIADOS

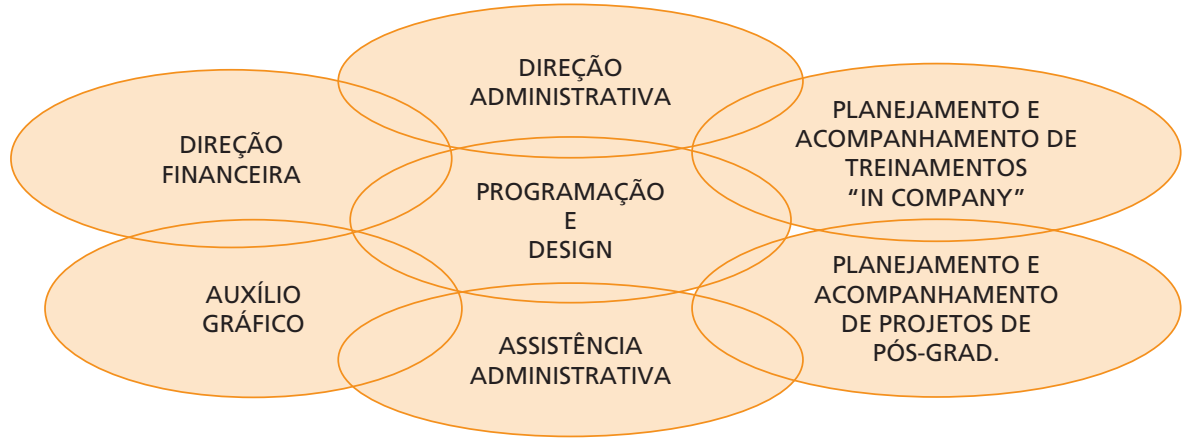

Conforme apresentado anteriormente, a empresa conta com três atividades principais - pós-graduação; treinamento in company; e recrutamento, seleção e outplacement - que são geridas pela direção administrativa e financeira, sendo suportadas pelas áreas restantes. Como salientado, a presente estrutura da forma 
foi constituída com base nas observações e entrevistas realizadas, com os objetivos de manter a interação constante, deixar claros os papéis e as competências de cada célula e evidenciar e cobrir possíveis carências de formação, evitando ao mesmo tempo sobrecarga e sobreposição de atividades, antes existentes.

A capacidade do modelo de gestão por competências de gerar respostas adequadas às atuais exigências do mercado, para todos os membros da organização, foi considerada inquestionável. Contudo, ressaltou-se a todos que a emergência e fixação de um modelo passam primariamente pela mudança de quem o implementa ou gerencia. Conforme argumenta Hurst (1996, p. 19), grande parte dos erros cometidos em um processo de mudança ocorre porque o administrador, geralmente, executa seu trabalho como se fosse um artesão que utiliza sua ferramenta no entalhamento de uma peça, muda-se a peça e não o artesão. Portanto, houve a conscientização da necessária mudança efetiva da postura dos gestores ante o novo modelo.

Como a abordagem da competência ainda está em construção, há abertura para várias composições do conceito, assim como há espaço para agregar e classificar essas competências de maneiras diferentes no contexto organizacional. Segundo Ruas (200I), um dos motivos que levam a essa constatação é que não se dispõe de bases conceituais estritamente confiáveis para se afirmar que uma abordagem é mais correta que a outra. O que define uma utilização mais ou menos "confiável" é o contexto. A aplicação do conceito na $2 \mathrm{M}$ Associados levou em conta muito mais os objetivos e as condições de sua aplicação do que uma decisão teórica ou técnica a priori.

Diante dos dados levantados, pôde-se concluir que a organização em análise tem como competências organizacionais o oferecimento de cursos de pósgraduação com qualidade nivelada com os demais existentes na cidade e região em que atua, com um preço sensivelmente inferior; a capacidade de organizar cursos com profissionais de outras regiões com experiência prática diferenciada; e a capacidade de organizar cursos customizados. Além disso, a empresa possui recursos importantes, como a posse de dois bancos de dados sempre atualizados - de professores e possíveis pós-graduandos - que permitem um marketing mais direto e parcerias mais adequadas. Com isso, a empresa tem acesso a profissionais e clientes que possam partilhar de suas necessidades, o que permite que ela ofereça qualidade diferenciada em seus serviços, a custos reconhecidamente similares aos dos concorrentes.

Em relação às competências individuais, optou-se por descrevê-las por células. Entendeu-se que, mesmo que haja substituições, as competências necessárias à atividade da célula estarão descritas. A seguir, serão apresentados os quadros de competências construídos para duas células, direção administrativa e 
planejamento e acompanhamento de treinamentos in company. Embora tenham sido construídos os quadros para todas as células, por questão de sigilo serão apresentados somente dois.

Como salientado nos procedimentos metodológicos, utilizou-se uma estrutura chamada de "quadro de competências", que segue premissas propostas pelos autores estudados e a lógica exposta na Figura 2. O processo de "montagem" dos quadros adotou a seguinte ordem:

- Definição da missão da célula: com base na missão da organização e em suas estratégias e objetivos, trabalhou-se no intento maior das células, nas suas razões de existência. As missões foram construídas em parceria com os membros da organização, discutindo-se qual seria o papel de cada célula na organização e como contribuiriam para o alcance das estratégias propostas.

- Com base nas missões, trabalharam-se as atribuições e contribuições. As atribuições referem-se às ações necessárias ao ocupante da célula, enfim, suas atividades diárias. As contribuições referem-se às responsabilidades da célula, e estas são definidas com base nas atribuições de cada célula.

- Pelas atribuições e responsabilidades definem-se as entregas e os indicadores de resultados. A entrega, conceito utilizado por Dutra (200I), indica o nível de resultados que a célula deve proporcionar perenemente. Os indicadores de resultados mostram e orientam sobre resultados cotidianos.

- Com base nos itens anteriores, definiram-se as competências necessárias para o(s) ocupante(s) das células cumprir(em) sua missão. Pela característica de prestadora de serviços, definiram-se competências relacionadas aos clientes e aquelas relacionadas aos serviços. A descrição dos resultados dos passos encontram-se nos quadros a seguir. 


\section{QUADRO I}

\section{COMPETÉNCIAS DA CELULA DIREÇÃO ADMINISTRATIVA}

Missão: Busca contínua pelo aperfeiçoamento dos serviços prestados e por novas oportunidades de negócios.

ATRIBUIÇÕES: (AÇÕES)

a) Articular a execução dos serviços prestados;

b) Negociar projetos;

c) Sustentar gerencialmente as células da empresa;

d) Buscar novas oportunidades de negócios.
CONTRIBUIÇÕES: (RESPONSABILIDADES)

a) Alcançar e manter a lealdade e satisfação dos clientes;

b) Manter a qualidade e o aperfeiçoamento contínuo dos serviços prestados;

c) Manter as competências adequadas à prestação de serviços.

INDICADORES DE RESULTADOS: (RESULTADOS DE CURTO PRAZO E ORIENTADORES)

- Número de projetos negociados no mês;

- Índice de satisfação dos clientes;

- Nível de satisfação dos funcionários;

- Fechamento de novos contratos/mês;

- Cumprimento das metas organizacionais.

- Elaboração e execução de estratégias alinhadas aos interesses da empresa.

\section{COMPETÊNCIAS EXIGIDAS DA DIREÇÃO ADMINISTRATIVA}

\section{RELACIONADAS AOS SERVIÇOS PRESTADOS:}

Capacidade de identificação de novos negócios que estejam ancorados nas áreas de competência da empresa;

Capacidade de coordenar a equipe ante os objetivos propostos;

Capacidade de articulação dos serviços prestados, aproveitando a sinergia advinda da integração.

\section{RELACIONADAS AOS CLIENTES:}

Capacidade de captar e analisar informações pertinentes a possíveis aperfeiçoamentos no nível de satisfação dos clientes;

Capacidade de antecipar e orientar as necessidades dos clientes.

Fonte: Elaborado pelos autores.

A definição das competências, conforme apontado anteriormente, passa pela capacidade de articulação dos recursos. Dessa forma, no processo de definição duas questões foram discutidas: a existência ou não dos recursos pertinentes às competências necessárias a cada célula e a capacidade de articulá-los. Os recursos de 
forma geral existiam, e poucos treinamentos foram sugeridos, no entanto faltava sua articulação perante "nortes" preestabelecidos, o que ocorreu depois da definição da missão e dos demais componentes dos quadros, ou seja, o próprio processo de construção dos quadros acabou por definir os "nortes”. A efetivação da verificação da capacidade de articular dos componentes das células advirá dos resultados alcançados, o que não coube no escopo deste trabalho que se limitou às definições.

\section{QUADRO 2}

\section{COMPETENCIAS DA CELULA PLANEJAMENTO E ACOMPANHAMENTO DE TREINAMENTOS IN COMPANY}

Missão: Elaborar, comercializar e acompanhar projetos de treinamentos ante as particularidades da demanda.

\section{ATRIBUIÇÕES:}

a) Organizar os diversos conteúdos presentes na empresa para elaboração de projetos;

b) Acompanhar e gerenciar os cursos;

c) Identificar necessidades de reorganização e inovação nos cursos;

d) Atender a eventuais necessidades das outras células da empresa.

\section{CONTRIBUIÇÕES:}

a) Elaborar projetos consistentes e de acordo com as necessidades dos clientes;

b) Manter o crescimento e a qualidade dos cursos oferecidos.

\section{ENTREGA:}

Execução dos projetos com a qualidade exigida.

\section{INDICADORES:}

- Número de projetos elaborados/projetos negociados ao mês;

- Índice de satisfação dos clientes.

COMPETÊNCIAS EXIGIDAS DA ÁREA DE PLANEJAMENTO E ACOMPANHAMENTO DE TREINAMENTOS IN COMPANY

\section{RELACIONADAS AOS SERVIÇOS PRESTADOS:}

Capacidade de agregar sistemicamente conteúdos para elaboração de projetos; Capacidade de rápida reação na readequação dos cursos com base nas "condições" da empresa a ser "treinada";

Capacidade de vislumbrar novas oportunidades de projetos e identificar possíveis sinergias entre projetos;

Capacidade de atrair e manter profissionais envolvidos com as necessidades dos cursos.

\section{RELACIONADAS AOS CLIENTES:}

Habilidade em identificar insatisfações e oportunidades no contato com os clientes; Habilidade em entender e negociar dificuldades com vistas à criação de fidelidade. 
As definições constantes nos quadros, embora auto-explicativas depois de prontas, foram um grande desafio para os membros da organização. Sentiu-se grande dificuldade dos membros em explicitar o que existia, mas era tácito. As próprias competências definidas carecem de aperfeiçoamento, contudo foi o máximo alcançado com a pesquisa. Conforme a prática, espera-se que todos os atributos dos quadros sejam melhorados, o que já é esperado por todos.

\section{CONSIDERAÇÕES FINAIS}

O presente estudo demonstrou que a definição de competências para uma pequena empresa, em conjunto com atributos que lhes dão dinamismo e coerência, proporciona organização, direcionamento e coerência. Embora Morin (2000, p. 92) afirme que o improvável se realiza mais que o provável, uma empresa sem um modelo mínimo de gestão tende à falência, conforme se observa nos índices e dados apresentados pelo Sebrae. Seguindo os preceitos da gestão organizacional, percebe-se que a correta definição dos indicadores presentes nos quadros de competência tende a diminuir a incerteza e o acaso na tomada de decisão, o que naturalmente leva à ampliação das chances de melhores resultados.

Embora os resultados com o modelo sejam satisfatórios, na fase inicial do processo de construção dos quadros de competências ocorreu grande desconforto interno. Primeiro, pela dificuldade dos membros em criticar o atual processo de execução das atividades. Não conseguiam sequer externalizar e explicitar suas práticas. Segundo, porque o modelo exige certa formalização no direcionamento nas ações, o que antes não existia. Todavia, com o desenrolar do trabalho e a visualização dos primeiros resultados expostos nos quadros, foi possível convencer os ainda céticos de que a organização proposta era realmente interessante e importante para empresa. A partir de então, houve um maior envolvimento e comprometimento no aperfeiçoamento e na definição dos atributos dos quadros. Isso se deveu também ao fato de todos, inclusive os gestores, já terem para si tacitamente a necessidade de uma melhor definição das atividades e de seus respectivos indicadores de resultado. Antes existiam na organização constantes atrasos nos serviços, retrabalhos e estresse na comunicação, além de dificuldade para identificar o foco. Assim, a possibilidade de "estruturar as ações organizacionais" sob a tutela de um modelo agregador e norteador agradou, envolveu e mobilizou a todos. Esse fato nos leva a concluir que efetivamente praticarão as exigências dos quadros de competências que eles mesmos ajudaram a construir.

Isso exposto e com vistas aos conteúdos dos quadros, verifica-se que os objetivos da pesquisa foram alcançados, ou seja, foram definidas as competências 
organizacionais e, célula a célula, as competências individuais e os meios necessários para mantê-las e desenvolvê-las.

A organização das áreas da $2 \mathrm{M}$ Associados por células e de suas respectivas competências - que ainda carecem de refinamento - permitiu à empresa um maior volume de conhecimento explícito sobre suas práticas e estratégias, além de um bom esclarecimento sobre o que é necessário para sua atuação. A empresa pôde também experimentar as benesses de um modelo de gestão, que surge como resposta a vários desafios presentes nas instituições em geral.

É importante ressaltar que o presente estudo se desenvolveu de forma que não incorresse no erro apresentado por Ruas (200I), o qual está muito presente em estudos sobre competências, qual seja: de as competências serem desenvolvidas distantes do contexto em que serão utilizadas. Neste caso, foram trabalhadas e definidas no e pelo próprio contexto de trabalho.

Diante disso, a presente pesquisa, embora apresente algumas limitações, como o tempo dedicado ao levantamento das competências organizacionais e o enquadramento em um modelo ainda em construção, serve como base para futuros estudos que desejam se aprofundar na verificação da aplicação do conceito e dos quadros em pequenas e médias empresas, com relação direta ou indireta com resultados financeiros.

Para finalizar, sabe-se que a prática é a principal responsável pela mudança de cultura e, conseqüentemente, de postura. Portanto, espera-se que a prática da nova estrutura, considerada ousada para uma empresa pequena, sirva de estímulo para que outras organizações experimentem o modelo e ajude a convencer vários pequenos empresários da necessidade e possibilidade de melhorar a gestão de suas empresas. Tendo em vista os resultados já experimentados na $2 \mathrm{M}$ Associados, vislumbra-se que a organização da empresa por competências gerará um efeito multiplicador e alavancador de novas práticas, novas idéias e novas atitudes diante da aprendizagem acumulada. O que permite que ela, de forma sustentada, mantenha e renove suas competências, ganhando valor econômico para si e proporcionando valor social para seus membros.

\section{REFERÊNCIAS}

ANTUNES, C. Como desenvolver as competências em sala de aula. Petrópolis: Vozes, $200 \mathrm{I}$.

BARBOSA, A. C. Q. ; RODRIGUES, M. A. Um olhar sobre os modelos de gestão de competências adotados por grandes empresas brasileiras. In: XXVIV ENANPAD, 2005, Brasília. Anais... Brasília, 2005. (CD-ROM)

BITENCOURT, C. C. A gestão de competências gerenciais: a contribuição da aprendizagem organizacional. 200I. Tese (Doutorado)-Universidade Federal do Rio Grande do Sul, Porto Alegre, 200I. 
BOTERF, L. De la competénce. Paris: Edition d'Organisation, I995.

Desenvolvendo a competência dos profissionais. 3. ed. Porto Alegre: Bookman, 2003.

BOYATZIS, R. E. The competent management: a model for effective performance. New York: John Wiley, I982.

CHANDLER Jr., A. Strategy and structure: chapters in the history of american industrial enterprises. Massachusetts: Cambridge, I990.

DUTRA, J. S. Gestão de pessoas com base em competências. In: FISCHER, André et al. Gestão por competências. São Paulo: Gente, 200I.

. Competências. São Paulo: Atlas, 2004.

ESCRIVÃO FILHO, E. A natureza do trabalho do executivo. I995. Tese (Doutorado)-Universidade Federal de Santa Catarina, Florianópolis, I995.

FLEURY, A.; FLEURY, M. T. L. Estratégias empresarias e formação de competências. 2. ed. São Paulo: Atlas, 200I.

GODDARD, J. The architeture of core competence. Business Strategy Review, Oxford, v. 1, n. 8, Iss. I, Spring I997.

GOLDE, R. A. Planejamento prático para pequenas empresas. São Paulo: Nova Cultural, I996. p. 7-34. (Coleção Harvard de Administração, v. 9)

HAMEL, G. Competindo pelo futuro: estratégias inovadoras para obter o controle do seu setor e criar os mercados de manhã. I3. ed. Rio de Janeiro: Campus, I995.

HURST, D. K. Crise e renovação: enfrentando o desafio da mudança organizacional. São Paulo: Futura, I996.

LONGNECKER, J. G.; MOORE, C. W.; PETTY, J. W. Administração de pequenas empresas. São Paulo: Makron Books, I997.

McCLELLAND, D. C. Testing for compentence rather than intelligence. American Psychologist, p.II4, Jan.I973.

MILLS, J. et al. Competing though competences. Cambridge: Cambrigdge University Press, 2002.

MORIN, E. Os sete saberes necessário à educação do futuro. 2. ed. São Paulo: Cortez, 2000.

OLIVEIRA JÚNIOR, M. Competências essenciais e conhecimento na empresa. In: FLEURY, M. T. et al. Gestão estratégica do conhecimento: integrando aprendizagem, conhecimento e competências. São Paulo: Atlas, 200I.

PERRENOUD, P. Construir competências desde a escola. Rio de Janeiro: Zahar, I999.

PRAHALAD, C. K.; HAMEL, G. The core competence of the corporation. Harvard Business Review, v. 68, n. 3, p. 79-9I, May/June I990.

PINHEIRO, M. Gestão e desempenho das empresas de pequeno porte. I996 Tese (Doutorado)-Faculdade de Economia, Administração e Contabilidade, Universidade de São Paulo, São Paulo, I996. RUAS, R. L. Desenvolvimento de competências gerenciais e a contribuição da aprendizagem organizacional. In: FLEURY, M. T. et al. Gestão estratégica do conhecimento: integrando aprendizagem, conhecimento e competências. São Paulo: Atlas, 200 I.

Aprendizagem organizacional e competências. Porto Alegre, Bookman, 2005.

RUAS, R. L. et al. O conceito de competência de A a Z - análise e revisão nas principais publicações nacionais entre 2000 e 2004. In: XXVIV ENANPAD, 2005. Anais... Brasília, 2005. (CD-ROM) SOUZA, M. C. A. F. Pequenas e médias empresas na reestruturação industrial. Brasília: Sebrae, I995. 
TERENCE, A. C. F. Planejamento estratégico como ferramenta de competitividade na pequena empresa. 2002. Dissertação (Mestrado)-Escola de Engenharia de São Carlos, Universidade de São Paulo, São Carlos, 2002.

THIOLLENT, M. Pesquisa-ação nas organizações. São Paulo: Atlas, I997.

VALLE, P. R. A; MACKE, J. Metodologia para identificação de competências em uma empresa de pequeno porte. In: XXVIII ENANPAD, 2004. Anais... Campinas, 2005. (CD-ROM).

ZARIFIAN, P. Objetivo competência: por uma nova lógica. São Paulo: Atlas, 200 I.

O modelo da competência. São Paulo: Senac, 2003.

WERNERFELT. B. The resource-based view of the firm: ten years after. Strategic Management Journal, v. I6, p. I7I-I74, I994.

\section{TRAMITAÇ ÃO}

Recebido em 3/9/2006

Aprovado em 26/3/2007 